\title{
LAW AND \\ DIGITALIZATION - \\ AN AGENDA FOR \\ THE FUTURE
}

LEGAL

TECH

LAB :ff
RESEARCH REPORTS

NO.1

May 2017

Riikka Koulu, Lila Kallio, Jenni Hakkarainen 


\title{
Authors
}

Ritkka Koulu

Lila Kallio

Jenni Hakkarainen

Ilkka Toikkanen
LL.D. trained on the bench, postdoctoral researcher, director of the Legal Tech Lab, University of Helsinki student, University of Helsinki student, University of Helsinki

\section{Layout}

student, University of Helsinki

\author{
University of Helsinki Legal Tech Lab \\ PO Box 4, 00014 UNIVERSITY OF HELSINKI \\ info@legaltechlab.fi
}

Follow us on Facebook, Twitter (@LegaltechHEL) and Linkedln!

\section{Published on 8.6.2017}

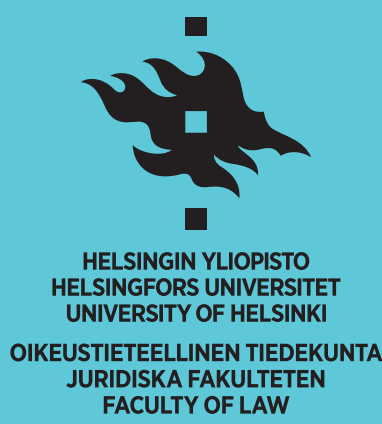

\section{LEGAL TECH $L A B$ :fi}

RIDISKA FAKULTETEN 


\section{Summary - Information, Dialogue and Engagement With a Twist}

The current state of affairs shows a strong need for action regarding legal digitalization. Even though the legal field is undergoing a transformation, there is not much research on digitalization and law. The lack of information needs to be remedied and The Legal Tech Lab aims to fulfill this need. The first steps are:

1) to define the phenomenon,

2) to establish best practices and

3) to actively create tools to facilitate navigating the legal system.

The steps are recursive and should be advanced jointly. The main objective of the work is to improve access to justice.

The Lab has many audiences that have partly overlapping and partly contrasting needs. First and foremost The Lab is an academic project produced together with all stakeholders from both the private and the public sector, NGOs, academics, students and anyone interested. Legal digitalization should be A COMMON EFFORT of all the stakeholders and hence they should be brought together whenever possible. The Lab's Advisory Board will meet twice a year and there will be collaboration with the board and the affiliated researchers.

The Lab deals in INFORMATION and facilitates dialogue. Information is at the core: The Lab is producing it, and collecting it from all the parties involved, including the Advisory Board, other interest groups and the participants of its events. The Lab is also disseminating information with an emphasis on knowledge mobilization both in academia and to the public using e.g. Facebook. The Lab's goal is to combine those with the need for information with those able to produce it. This will be accomplished by commissioned studies and the thesis bank initiative. Commissioned studies can include e.g. giving the public sector recommendations on policy setting, providing tools for individuals and developing parameters for responsible digitalization. Dealing in information is fitting, as information is the primary asset of the Information Age.

The two ways of producing academic DIALOGUE with a twist:

1) Big mixed academic events are a way of producing hype as well as bringing people together, e.g. June 9 , 2017 conference "Law and Digitalization - Rethinking Legal Services" where attention is paid to the visuals, interviews and panels instead of one-way presentations, students presenting their work and mixing academics with professionals as well as tech people with lawyers.

2) Genuine dialogue and collaboration requires smaller informal settings. The Lab's work aims to blurring the line between research, education and community relations.

ENGAGEMENT: hackathons and start-up incubators are a way of encouraging students towards these themes and of bringing together business interests and supporting the legal tech scene. The public sector could also benefit from pilot projects designed and organized with the Lab (e.g. hackathons).

\section{COMMUNICATION STRATEGY:}

1) Emphasis on visibility - new methods of knowledge mobilization (e.g. the use of social media).

2) Blurring the line between national and international - the Lab's work is made accessible through English language when possible. The Lab is committed to interdisciplinary co-operation both in and outside of academia and it works closely with its professional contacts.

3) Crossing disciplinary boundaries - the Lab actively seeks influences from both law and IT fields. 


\section{CONTENTS}

1 Introduction

Digitalization of Legal Practices

What is the University of Helsinki Legal Tech Lab?

About this Report

2 Objectives

I a) Unbiased Information on Digitalization of Law

I b) Academic Thought Leadership on a National Scale

Ic) Designing a Brand for the Law Faculty

Id) Education for Tomorrow's Lawyers

II) Creating Space for Stakeholder Interaction

III a) Encouraging the Legal Market to Develop

III b) Promoting Economic Action in Legal Tech

IV a) Community Relations and Social Responsibility

IV b) Providing Topical Themes for Public Debate

\section{Target Groups}

Academics

Students

Lawyers

The Public Sector

Businesses

End users 
Digitalization of Public Services

Global Conflict Management

Harnessing New Technologies

Open Data and Access to Legal Information

Shaping the Future of Legal Profession

Legal Technology Studies

For the Academic Community: Research Activities

For the Students: Legal Training Together with Professionals

For Lawyers: Continuous Training

For Businesses: Dialogue, Collaboration and Support

For the Public sector: Dialogue, Recommendations and Information for Policy Setting For the Overall Society: Community Relations

Collecting and Disseminating Information on Legal Tech and Digitalization of Legal Services 


\section{Digitalization of Legal Practices}

Digitalization is the buzzword of today. The term is used to refer to the transformation of industries, human interaction and our ways of being, our societies. ${ }^{1}$ Digitalization of legal practices is a part of this overall development. Despite the hype, there is a severe lack of unbiased information available on the consequences of digital shift for the practice and study of law.

This report produced by the University of Helsinki Legal Tech Lab strives to be the first step to remedying this lack of information. Based on the experiences and impressions crowdsourced from the Lab's prestigious Advisory Board, the report 1) provides insight into the current state of digital transformation in the legal field and issues at hand, and 2) maps out the future agenda for the Lab.

It should be noted that in our terminology, there is a difference between the terms 'digitization' and 'digitalization' and the terms should not be used interchangeably. According to the Oxford Dictionary, 'digitization' means "the conversion of text, pictures, or sound into a digital form that can be processed by a computer". ${ }^{2}$ We perceive 'digitalization' as a broader concept that is used to describe the system-level changes the adoption of new technology brings forward. In this meaning, digitalization is linked with the concept

\footnotetext{
1 See e.g. The report commissioned by Google and drafted by the Boston Consulting Group that calls for European action to secure growth in the EU in the future. Emmanuelle Alm, Niclas Colliander, Filiep Deforche, Fredrik Lind, Ville Stohne \& Olof Sundström, "Digitizing Europe. Why Northern European Forerunners Must Drive Digitization of the EU Economy", The Boston Consulting Group: May 2016, p. 3. Report available at: http://image-src.bcg.com/BCG_COM/BCG-Digitizing-Europe-May-2016_tcm22-36552.pdf (accessed March 9, 2017). 2 https://en.oxforddictionaries.com/definition/digitization (accessed March 9, 2017).
}

of disruptive technology - a term originally coined by Joseph Bower and Clayton Christensen already in 1995. ${ }^{3}$ By making the distinction between sustaining and disruptive technologies, they explained, why market leaders often fail to respond to fundamental changes in markets and why game-changing technologies are often developed by outsiders. Within the legal field, Professor Richard Susskind borrows Boer and Christensen's terminology and identifies several disruptive technologies that will fundamentally challenge the traditional practice of law. ${ }^{4}$

It is rapidly becoming self-evident that the implementation of information and communication technologies (ICT) to the legal field creates ruptures in the structures of law. These ruptures may adopt several different forms from the corrosion of the state's monopoly on violence to shifting business models of law firms. In short, the digitalization of legal practice affects diverse interest groups including law firms, courtrooms, businesses, and individuals.

It is important to understand the temporal perspective of digitalization. The beginning of this shift can be traced back to the 1980s, where the adoption of ICT in the legal sector became mainstream. The change is still on-going in courthouses, law firms, start-ups and other arenas of legal action that face the challenge of updating their modus operandi. According to estimates of the multinational accounting firm Deloitte, the tipping point for law firms that do not prepare for the disruption will be in 2020 , after which they are no longer sustainable. ${ }^{5}$

\footnotetext{
3 Joseph L. Bower \& Clayton M. Christensen, "Disruptive Technologies: Catching the Wave", Harvard Business Review 73:1 (1995), pp. 43-53. 4 Richard Susskind, The End of Lawyers? Rethinking the Nature of Legal Services, Oxford: Oxford University Press 2010, p. 93-.

5 Creative Studio at Deloitte, "Developing legal talent. Stepping into the
} 
In light of this situation the need for unbiased information is only emphasized. When carried out without paying heed to the challenges and pitfalls, the potential of digitalization might deflate into simply repeating the old working methods in a digital environment. If we are to transform the way in which legal services are provided and ultimately reassess the structures of law, the evaluation of both the possibilities and the challenges is necessary. For this end the University of Helsinki Legal Tech Lab was created in November 2016.

\section{What is the Legal Tech Lab?}

The Legal Tech Lab is a non-profit interdisciplinary pilot project at the Faculty of Law, University of Helsinki, which examines and experiments on legal tech and digitalization of legal practices. ${ }^{6}$ The Lab provides a venue for dialogue between all stakeholders involved in legal digitalization, produces information and research, and trains the future generations of lawyers to work in the new digital environments.

The Lab's objective is to raise awareness about the possibilities of legal tech and its implications on fundamental rights of individuals, provide critical insights into technology and create a one-stopshop for academic and practical information on digitalization of legal practices both nationally and globally. In a manner of speaking, the Legal Tech Lab is the law faculty's in-house start-up, which combines hands-on experimentation with legal technology with in-depth academic research.

The Lab's three objectives are linked with the functions of university: research, education and community relations. This means that in addition to its research goals the Lab adopts a responsibility for training future lawyers to function in the changing digital environment and participates in public debate on the best digitalization practices. Although these functions should be seen as taking precedence, the lab's work is best supported through active dialogue with all stakeholders and interest groups. This collaboration ensures that the Lab preserves its forward-looking approach and facilitates knowledge mobilization.

\section{About this Report}

This report contains valuable insights crowdsourced from the members of the Lab's Advisory Board during working group discussions held at the Lab's Launch on February 15, 2017. The Advisory board is comprised on legal professionals, IT specialists as well as academics who all are experts of the interface between law and technology.

The report has a dual function of describing the current digitalization-related needs of the legal sector and mapping out the possible goals, projects, activities and other actions that the Lab should take on to its agenda. Hence, the report provides an overview of the field on a national scope. However, the ultimate objective of the working groups was to define the scope of the Lab's work and to identify core problems. Four areas are covered in this report, 1) objectives that the Lab should adopt, 2) target groups that should be involved in the Lab's work, 3) thematic areas that should be covered, and 4) suggestions for concrete activities. This report is structured following these areas that are covered in sections 2 to 5 . In the last section there is an overview of the Lab's future agenda.

future law firm", London 2016. The report is available at: https://www2. deloitte.com/uk/en/pages/audit/articles/developing-legal-talent.html (accessed March 8, 2017).

6 www.legaltechlab.fi 


\section{Objectives}

According to the opinions raised in the working groups, The Legal Tech Lab should pursue several objectives simultaneously. These perceived objectives relate both to the traditional functions of the university as well as to facilitating the birth of a legal tech startup culture in Finland. Some of the groups translated the question of objectives into an issue of roles. However, concern was voiced in some discussions about the fragmentation of the lab's resources, if the lab is to adopt several contrasting roles.

In this section, the main issues raised by the working groups are discussed in further detail. These objectives can roughly be divided into four categories: 1) academia and legal education, 2) creating a space for interdisciplinary dialogue, 3) promoting the adoption of legal tech and best practice of digitalization, 4) community relations and social responsibility. As a university project the Lab's emphasis should be on research and training. However, the other objectives support these primary goals by introducing new ideas for research and by disseminating the accumulated knowledge to practice. Hence, boundaries between these objectives are not - and should not be understood as- exclusionary but instead different interests and objectives coincide in the Lab's working methods to create a platform for incorporating best practices of legal digitalization overall.

The advantage of a non-profit university project is that it enables the Lab to react quickly to changes in the field. This means that objectives should be general enough to enable change but simultaneously the scope needs to be concise enough not to lose focus. In order to cross the divide between theory and practice, the Lab needs to host concrete projects with a hands-on attitude.

\section{I a) Unbiased Information on Digitalization of Law}

Currently, there is a significant lack of information on digitalization of law. ${ }^{1}$ As digital revolution proceeds in all areas regardless of this deficiency, our legal system is facing the possibility of digitalization gone wrong. Implementation of disruptive legal technology is a complex and multifaceted process that has potentially significant impact on the ways how access to justice is provided for. In order to provide tools for best practices of legal digitalization, the first step is to remedy the lack of unbiased information.

The most important objective for the Lab is to remedy the lack of unbiased information that currently hinders legal digitalization. The university and the law faculty have a strong identity in producing basic research. This emphasis on basic research should be the starting point also for the Lab's academic objectives. The Lab should promote basic research on subjects related to the interface between law and technology, legal technology and digitalization of legal practice.

The knowledge constructing interests are various. Firstly, the Lab should aim at producing an overview of legal digitalization by providing definitions and structures for future research. This work can be called pre-paradigmatic, as these fundamental concepts are necessary for laying out the groundwork for establishing the field of law and digitalization. Especially this groundwork requires continuous dialogue with all

1 The law faculty at the University of Lapland hosts the Institute for Law and Informatics and legal informatics is taught as a part of the faculty's curriculum. However, the institute approaches technology from the perspective of informatics. See e.g. https://www.ulapland.fi/InEnglish/ Units/Faculty-of-Law/Institutes/Institute-for-Law-and-Informatics/ Introduction (accessed 22 March 2017). 
stakeholders and interest groups in order to provide sufficient framework. In addition, empiric approaches should be included in order to maintain a close connection between theory and practice. Secondly, the Lab's work should recognize and examine the specific areas in different branches of law, where more detailed and concrete de lege ferenda research is needed. Thirdly, the Lab's academic activities should promote inclusion of technology-related subjects and the adoption of user centric approach in other areas of basic research.

The Lab's research activities should be reflexive to technological innovation. For example, information on topical phenomena should be produced expediently. For this to succeed, it is important that the stakeholders maintain active contact with the lab so that these knowledge constructing interests can be recognized. However, the Lab should preserve the viewpoint of improving the end users' access to justice through technology in all its academic activities.

It should be noted that conducting the research does not suffice alone. The results should be disseminated properly and active attention needs to be paid to informing not only stakeholders but also the public about the importance of legal digitalization. In addition to academic publishing, the Lab's knowledge mobilization strategy needs to include active presence in social media (Facebook, Twitter, etc.). The Lab should also participate in the public debate on digitalization both offline and online.

\section{I b) Academic Thought Leadership on a National Scale}

Currently, there are no academic actors in Finland that focus on digitalization of law. However, the need for unbiased information mentioned in the previous section can only be provided by a neutral academic actor that has sufficient knowledge about the functioning of the legal system. In order to rectify this situa- tion on a national level, one of the law faculties needs to actively pursue this neglected field.

Hence, there exists the possibility for the Law Faculty at the University of Helsinki to adopt the role of academic leadership in this field both nationally and internationally through the Legal Tech Lab. The digitalization of legal practices is well underway both in the private and public sector, calling for academic action in the field. The Legal Tech Lab has the potential to establish itself as a hub of legal digitalization. To accomplish this task, the Lab needs to challenge the image of academic projects as reactive and pas-

sive and become the channel for new ideas. One way to achieve this is to examine similar projects abroad that have become successful, e.g. Berkman Klein Center at Harvard Law School.

\section{I c) Designing a Brand for the Law Faculty}

At the moment there are several researchers whose work touch upon different aspects of digitalization of law, e.g. copyright issues, robotics, online dispute resolution, platforms etc.. Still, the field is fragmented and knowledge produced by researchers does not find its way to stakeholders. In other words, there exists a gap between academic and professional knowhow and research results are not disseminated properly. This situation calls for the creation of an umbrella organization that combines the researchers and their work under easily accessible unit that can promote the academic activities in this field in order to provide better understanding of legal digitalization in the society.

The Legal Tech Lab should also be understood as a means of brand creation for the Law Faculty. By creating a strong brand, the Lab could attract both national actors, such as law firms, tech companies, the justice department etc., but also foreign academics. Through 
careful branding the Lab can potentially increase the attractiveness of Helsinki as a legal tech hub. Because of its specific focus on law and technology, the Lab should strive for becoming a connection point for actors in the field, thus lowering the threshold for initiating contact.

As the Law Faculty's in-house start-up, the Legal Tech Lab should pursue relatively aggressive and vocal brand. A key ingredient in achieving this is active communication through social media in addition to the more traditional communication channels. The Lab should perceive the overall society as well as the stakeholders and interest groups as customers and aim at answering the needs of these instances. However, the Lab's brand derives its strength from the additional informational value produced through different academic projects. It should be noted that the Lab's brand is first and foremost based on its role as a neutral actor.

$\longrightarrow$ One of the objectives is to increase the importance of the Law Faculty at the University of Helsinki in matters related to law and technology. In order to achieve this objective, it is necessary to create a longlasting brand for the Lab as the connection point between all actors in the field.

\section{I d) Education for Tomorrow's Lawyers}

Currently, themes related to law and technology are taught in individual courses at the Law Faculty of the University of Helsinki. However, these courses delve into specific fields of law and do not sufficiently contribute to the creation of an overview of legal digitalization. The skillset demanded of lawyers in the future sets additional requirements for their education at the law faculty. Future lawyers will graduate into a significantly different working environment than their peers in the past, which means that they need to understand the shift taking place in the digitalized legal practices.

As an academic endeavour, the Lab should provide education for law students who need to come to terms with digitalization of legal practices when they enter the labour market. However, the Lab should include law students in its activities in different roles and not perceive them only as passive recipients of information. Instead, the Lab can encourage student initiative in creating content as well as promote entrepreneurship among students. To this end, the Lab can create interdisciplinary projects and classes to encourage law student to interact with students from other fields.

\section{II) Creating Space for Stakeholder Interaction}

There exists no neutral meeting ground for stakeholders who have a common interest in law and digitalization. However, interests of different stakeholders are often overlapping and, even when they are in juxtaposition, dialogue would improve our understanding about interdependencies and thus facilitate the cumulation of information. This, in turn, improves the possibilities for collaboration.

One of the most focal opinions raised in all working groups was the importance of creating a space for interdisciplinary interaction. Although working groups described this in different terms, all recognized the need for collaborative space. According to some, the Lab should be a base for academic and practical actors, others hoped to see the Lab becoming a network.

This urge for structured dialogue stems from the status quo, where digitalization of legal practices is on-going and collaboration between different actors is required but no instance has taken the lead for coordinating exchange of ideas between stakeholders. In addition, the existing models of co-operation are not applicable to technology-specific collaboration as such. As there is a lack of common ground, the Lab could easily gain momentum by providing structure for such exchanges.

In order to promote the adoption of best practices of 
legal digitalization, it is necessary to cross the divide between academia and practice as well as to enable exchange of ideas between lawyers and representatives of other disciplines. Due to its academic status, the Lab constitutes a neutral meeting ground that is ideal for such interaction. It is important that the dialogue enabled by the Lab is interdisciplinary. In addition, the dialogue should cross the divide between academia and legal professionals, which is rendered possible by emphasizing concrete problem solving in different projects.

\section{III a) Encouraging the Legal Market to Change}

According to some estimates, the practice of law is facing significant changes in the upcoming decade. The need for change is also evident in the court system, which has gone through severe budget cuts. In short, the legal market as it is needs to change if it is to maintain its importance.

Several working groups took notice of this bigger picture involved in the Lab's work. The groups perceived that ultimately the objective of the Lab's activities is to encourage the Finnish legal market to change in order to accommodate the needs of the surrounding society. This objective is directed towards the legal profession and legal institutions such as law firms, courts, dispute resolution boards, and administration among others. In addition to establishing a body of work on the best digitalization practices, the Lab should provide concrete examples and pilot projects for these actors. For example, the Lab could work as a go-between for these institutional actors for experimenting new technological solutions through hackathons and other pilot projects.

\section{III b) Promoting Economic Action in Legal Tech}

Currently, the legal tech scene in Finland is relatively new. There are only a couple of legal tech start-ups that have gained broader acknowledgement. These include well-known examples of TrademarkNow, Turre Legal and ContractMill to name but a few. However, responding to the need for innovation in the legal sphere requires a vibrant community of legal tech start-ups in addition to giving support to existing actors in transforming the existing services. In order to be successful, legal technology needs to be developed in co-operation between lawyers, designers and programmers. This, in turn, requires common ground for interaction and sufficient support for emerging ideas. The Lab can facilitate the creation of a legal tech start-up culture in Finland by various means.

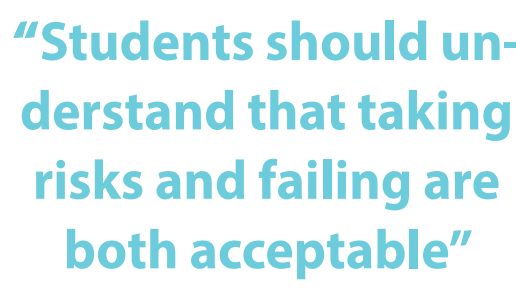

In addition to developing tools for the established actors, the Lab's work should also encourage disruptive innovation in the market. Such disruption is most likely pursued by legal tech start-ups that come from outside the established markets. The working groups recognized four different ways of promoting economic action in legal tech.

Firstly, the Lab should tap into its obvious asset, students, and as a part of the law faculty's curriculum encourage law students towards the emerging legal tech market. Typically, law students who wish to work in the private sector still perceive traditional career choices in law firms as desirable and few students find employment in start-ups or in digital design. This is also related to the public image of lawyers as experts in the traditional sense, who are required to complete several years of apprenticeship before earning their position. For these reasons it is important to demonstrate that entrepreneurship is a possible career option also for lawyers. For this to succeed, students should understand that taking risks and failing are both acceptable. Also, the Lab should promote interaction between law students and students from other fields to mitigate the often conservative mindset of lawyers. Still, students' interest in law and technology is the first 
step towards encouraging them towards alternative career options. This means that the Lab needs to create and maintain students' interest by creating activities particularly designed for students.

Secondly, the Lab could also provide support for the development of legal tech field by recognizing and communicating problems that are prime candidates for automation due to the relatively low value of interests involved and the potential scalability of potential solutions. An example of such technological innovation can be found in the DoNotPay chatbot that provides drivers an easy way to contest parking tickets. ${ }^{2}$

Thirdly, the Lab could encourage the emergence of new start-ups by organizing hackathons and start-up incubator services such as coaching for newly founded legal tech start-ups. Demonstrating the problem areas where new technology is needed pinpoints preconditions for developers. Fourthly, the Lab could include businesses in its research projects that would combine both the theoretical and the practical.

\section{IV a) Community Relations and Social Responsibility}

\begin{abstract}
It has been noted in several studies both nationally and internationally that Western legal systems are facing severe problems in providing access to justice. Algoritmic law and legal technology needs to be developed responsibly, if we are to encourage access to justice through the use of technology instead of obstructing it. Hence, the social responsibility needs to be emphasized at each step.
\end{abstract}

All the working groups recognized that the Legal Tech Lab serves first and foremost the whole society. As an academic actor, the Lab should by no means cater to the needs of individual stakeholders but instead focus

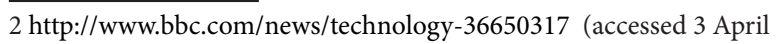
2017). on improving access to justice. This accentuates the importance of community relations and social responsibility. Also, the social focus on the Lab's work is also a means for creating far-reaching impact. In other words, the Lab's activities have a dual function on serving both the public, in the meaning of the larger legal community, and the specialized legal practices, such as policy making. At the core of these activities is the production of information that provide an overall picture of the consequences digital transformation has on access to justice.

A key element here is to identify the problem areas, where ordinary people have to come to terms with the legal system. Several studies have shown that these encounters between individuals and the legal system are often perceived as ineffective or

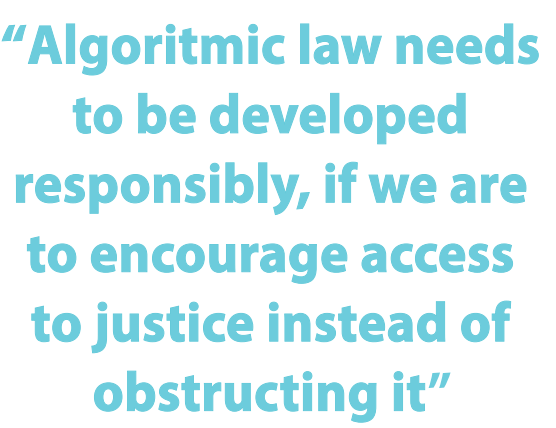
even traumatic, as navigating the legal system often requires either expert knowledge or access to often expensive legal advice. In other words, accessing the legal system for demanding one's rights often translate into bad user experiences (UX). Recognizing these problems is the first step in finding solutions. Only when information about these problems is made available and discussed in the public sphere, does it become possible to adopt solutions that could promote access to justice with the help of legal technology. This improved UX, in turn, would translate into a broader trust in the public administration of justice.

In addition, successful digitalization of legal practice requires in-depth analysis of different policy options. Hence, information needs to be provided also for the purposes of policy making in order to enable effective adoption of technology.

$\longrightarrow$ The legal system as we currently know it does not cater well to the needs of self-presenting litigants. The Lab should 1) promote the creation of user- 
friendly software and 2) contribute to improving the end-users' experiences by adopting and promoting a user-centric perspective both for the public debate and for policy making.

\section{IV b) Providing Topical Themes for Public Debate}

As stated, digitalization of law is a complex phenomenon that affects everyone regardless of social status, wealth, education or employment. Successful implementation of technology cannot be achieved simply by lawyers but instead it requires a public debate on topical themes related to digitalization of law. The Lab should keep such themes on the agenda and encourage open discussion.

As an academic endeavour, the Lab should provide a critical insight into legal digitalization. Currently, it is unclear how exactly implementation of technology will change legal practices or transform the legal market, although some examples of disruption can already be evaluated. However, there exists a multitude of different and contrasting interests, which makes it harder still to evaluate the correctness of information provided by stakeholders. Hence, academia should maintain an active presence in the public debate to provide more comprehensive information for decision making.

Embracing the experimentation culture enables quick shifts to new topical themes without undue delays. The Lab should hold different types of events for different audiences to test new ideas and to create dialogue. For this to succeed, it is necessary that the Lab's scope is not limited to specific themes but new ideas are put to test without prejudice. Also, theoretical approaches should be complemented with concrete examples and applications, as concreteness provides an easy access point to relevant discussions.

Dissemination of results and general knowledge mobilization play a key role in realizing the Lab's objectives 


\section{Target Groups - \\ Who Should Have a Say?}

The working groups discussed potential target groups that would benefit from the Lab's work. Naturally, the potential target groups are connected with the project's overall objectives. However, detailed description of intended audiences contributes to creating the overall picture of the status quo.

\section{Academics}

The digitalization of law and the potential of legal technology has not been discussed in any detail in legal scholarship. The critical first step for creating an informed body of work about legal digitalization is to establish a systemic framework for future research. This means overcoming the challenges of the preparadigmatic nature of law and digitalization by demonstrating the importance of these themes for future legal scholarship as well as developing a functional methodology for legal technology studies. Hence, the academic community as a whole, including university teachers, professors and lectures as well as doctoral students, is a self-evident audience for the Lab's research activities.

\section{Students}

As discussed above, education of future lawyers to function in the shifting digital environment is necessary for successful legal digitalization. Law students need to be informed about issues related to law and technology as well as encouraged to interact with students and professionals from other fields.

\section{Lawyers}

One of the target groups for the Lab's activities are lawyers currently employed in all areas of the legal system ranging from law firms and businesses to the courts, legislative branch and public administration. Although significant advances are being made to develop new technological tools for the legal sector, lawyers still rely mostly on word processing tools and their own cognitive skills. It is important to develop new tools for lawyers also in the national context, which is challenging considering the small size of the linguistic area. In addition, lawyers are in need of continuous training.

\section{The Public Sector}

The public sector plays an important role in legal digitalization. Important public actors related to digitalization of legal services are the ministries, the legislative branch, the courts and other public dispute resolution providers such as The Consumer Disputes Board (Kuluttajariitalautakunta) or The Appeal Board for Social Security (Sosiaaliturvan muutoksenhakulautakunta).

The legislative branch could benefit from specialized software tools developed for the specific needs of policy making. In addition to this, successful legal digitalization requires on-going analysis of the possible regulatory needs, which, in turn, is made possible with unbiased information produced in academia.

The public court system is nationally the primary provider of dispute resolution services for both individuals and SMEs. This means that the Ministry of Justice is also an important customer for software companies that produce legal tech software for the national market. ${ }^{1}$ There is potential in improving access to justice

\footnotetext{
1 For example, the data bank initiative AIPA creates a case management system that will be used by all public courts, prosecutors and attorneys. See, Syyttäjälaitoksen ja yleisten tuomioistuinten asiain- ja dokumentinhallinnan kehittämishanke AIPA, 30.3.2017, available at: http://oikeusministerio.fi/fi/index/valmisteilla/kehittamishankkeita/ syyttajalaitoksenjayleistentuomioistuintenasian-jadokumentinhallinnankehittamishanke.html
} 
through implementation of technology but tapping into this potential requires extensive cost-benefit analysis and knowhow. In short, the public sector, including the legislative branch, the courts and judicial administration in general are a major stakeholder in legal digitalization.

\section{Businesses}

Different businesses also have an invested interest in legal digitalization. Established leaders of the legal market, law firms, are facing the challenge of reforming their business models, whereas emerging start-ups are providing disruptive legal technologies. Also big software companies play a role in developing new tools for lawyers both in the private and the public sectors. In addition to these, SMEs outside the legal sphere could benefit from legal software. Notedly, these private sector actors have di-
uThe user-centric perspective has mostly been lacking in discussions about the future of law and this situation needs to be remedied" verse needs related to legal digitalization. The Lab would benefit from input from all these stakeholders and also provide insight to them for navigating the changing operational environment.

\section{The End Users}

However, the most important target group for the Lab's activities are the end users of legal practices. This means individuals, businesses and NGOs in their different roles as clients of the legal system. The user-centric perspective has mostly been lacking in discussions about the future of law and this situation needs to be remedied. It should be noted that end users of the legal system do not form a uniform group but are a fragmented whole that includes also groups with special needs. The elderly as well as people with disabilities need to be included into legal digitalization and special attention should be paid to their needs in order to prevent marginalization. The needs of special groups pinpoint the way to the pressing question of how the shift to the digital environment impacts fundamental rights of individuals.

$\longrightarrow$ There are several groups that potentially have invested interest in the work of the Legal Tech Lab. These interests are partly overlapping and partly contrary and the Lab should position itself at this crossroads as an intermediary

$\longrightarrow$ The Lab's strength is in its potential to gather together a multitude of different actors and to enable plurality of voices 
The working groups also discussed possible themes that could be taken into consideration in the Lab's academic programme. However, several groups emphasized the need for comprehensive scope. Themes discussed in this section should not be seen as exclusive but more as examples of possible future work.

\section{Digitalization of Public Services}

Digitalization of public services comes with diverse set of questions that bear legal relevance. The Lab should pursue creating the blueprint for the societal change that affects individual citizens and other regulatory subjects on national level. This theme is connected with the difficulties of public procurement of software systems. The public sector's track record on software acquisitions has been somewhat unsuccessful and the reasons behind this and possible solutions should be mapped out in research. Also, the digitalization of public sector carries the potential of providing easier access to legal information, which, in turn, is the prerequisite for actual access to justice. Improving individuals' access to information and facilitating navigation within the legal system by legal design, benefit especially self-presenting litigants and increase legal protection and overall trust in the public administration of justice.

Concrete on-going examples of digitalization of public services include the creation of national service architecture and the comprehensive social services reform (SOTE).

\section{Global Conflict Management}

Globalization of law is affecting also the legal system and the legal market. Legal tech start-ups perceive their markets as global, where as the need to comply with differing regulatory frameworks creates barriers for development. Increase of cross-border ecommerce generates issues of consumer protection especially as consumers have very limited means of accessing dispute resolution in case something goes wrong. Also disputes arising from global technological innovation create the need to develop effective dispute resolution mechanisms that avoid the jurisdictional challenges of traditional cross-border litigation in the courts. The need for new solutions became even more evident in the aftermath of the multi-million euro hack of the DAO, the distributed autonomous organization built on the blockchain, in summer 2016.

In other words, issues related to global conflict management, both pre-dispute and after a dispute has already risen, constitutes a major theme for the Lab's academic agenda.

\section{Harnessing New Technologies}

New technologies can be used for the benefit of improving access to justice. Tapping this potential requires thorough examination of the possibilities, challenges, pitfalls and best implementation strategies, because the consequences of badly conducted implementation on legal certainty are not acceptable. Currently, there is promise in legal automation, machine learning, data analytics and in blockchain applications that should be evaluated.

In addition, new technologies give rise to new in- 
terpretative problems. For example, copyright in digital environment as well as privacy of children demonstrate the limited use of analogies in tackling the need for new approaches.

\section{Open Data and Access to Legal Information}

As stated above, access to information is the necessary first step towards legal protection. Opening legal data to everyone would contribute positively to access to justice and enable the creation of new user-friendly tools for navigating the legal system without expert knowledge.

uThe Lab could offer a hulb for collecting legall data and distributing it openly for the public benefit"
For example, case diagnosis tools, process descriptions, case management, e-filing assistants, links to relevant authorities and legal aid programmes as well as mediation tools could benefit self-presenting litigants and individuals who are facing a potential dispute. The Lab could offer a hub for collecting both publicly and privately produced legal data and distributing it openly for the public benefit.

\section{Shaping the Future of Legal Profession}

Legal services have traditionally been rendered as tailor-made solutions to individual cases of individual clients. However, the profession is changing as more and more cognitive tasks can be automated. Due to this, law firms are reassessing their business models and the role of a lawyer is gradually shifting away from artisanal labour. Machine learning, neural networks and automation all deal with information and designing (as well as using) different applications of these technologies within the legal system creates the need for new working methods. Instead of artisans, lawyers need to possess skills such as data analytics. The change in legal profession needs to be addressed both in research and legal training.

\section{Legal Technology Studies}

In order to implement technology to the legal system with minimum repercussions, it is necessary to develop legal technology studies. We need to adopt a nuanced approach to technology that addresses the specific needs of the legal system as a functionally differentiated societal subsystem. This means that applications of information technology should be seen as context-based and diverse, and generalized presumptions should be contested. For example, the use of ICT does not automatically bring efficiency or added value to processes nor give voice to marginalized groups, although in some cases these presumptions might prove out to be true. More diverse understanding of ICT and particular use cases leads to asking the right questions to secure responsible digitalization. Securing transparency and battling harmful phenomena such as automation bias are issues that can be addressed sufficiently only through legal technology studies. 
The activities organized by the Lab should cater to the diverse and sometimes contrasting needs of different target groups. This means organizing different types of activities for different audiences and creating plenums that include all stakeholders for discussing overlapping themes.

\section{For the Academic Community: Research Activities}

The Lab's activities that are directed towards the academic community should emphasize its objectives. Information produced by the Lab should be easily accessible and follow the university's open access policy. Research should be disseminated on the Lab's website as well as through other communication channels.

$\longrightarrow$ Open access policy for the Lab's publications

The research agenda should emphasize the Lab's interdisciplinary approach and include academics from other disciplines as well as co-operation with stakeholders from private and public sectors to research projects when possible. Among other things, this means that academic activities should not be designed or marketed only to academics. Instead, seminars, conferences and talks should follow the Lab's interdisciplinary approach and include all actors. However, academic content must be produced on the university's terms and maintain high academic quality. The dialogue between theory and practice should be encouraged with the out-spoken intent to recognize problem areas for future research.

workshops and seminars to encourage interdisciplinary dialogue between theory and practice
The Lab's work should produce a blueprint for legal digitalization. The first step towards this is to define what is legal digitalization and to recognize the problem areas where digital tools could improve access to justice. The second objective is to provide a systemic framework for legal technology studies. This work is pronouncedly international, although preserving a national perspective is also vital to accommodate the needs of the public sector and overall society. Research activities with the affiliated researchers should aim at applying and securing funding from prestigious instances such as the Academy of Finland and the EU.

$\longrightarrow$ research report on digitalization and problem areas

$\longrightarrow$ international conferences and publications

$\longrightarrow$ creating a research networks for collaboration with the objective of applying for Academy of Finland and EU funding calls

\section{For the Students: Legal Training Together with Professionals}

Activities directed to students should accentuate the training aspect and introduce new forms of legal education, e.g. hackathons to the law faculty's curriculum. More advanced students who are about to start writing their LLM theses should be encouraged to specialize in technology-related areas. One way to promote themes of legal digitalization is to create a thesis bank that matches students with businesses in need of research on concrete problems. Students should also be involved in research projects and boundaries between the university's different functions should be diminished. Students could gener- 
ate materials and contribute to research projects and take on an active role in designing future training and activities.

In order to promote the creation of legal tech scene in Finland, it is important to demonstrate to students that there are alternative career options for lawyers. For example, institutional co-operation with Aalto University could be one way of achieving this.

$\longrightarrow$ new forms of education, e.g. legal tech hackathons

$\longrightarrow$ The Thesis Bank Initiative

$\longrightarrow$ national web course Introduction to Law and Technology

\section{For Lawyers: Continuous Training}

The Lab's educational focus should not be limited to law students but instead training possibilities should be aimed also at lawyers currently working in legal services. Lawyers affected by digitalization of law might be employed in law firms, in the court system, in administration or in private sector. These lawyers will face the need to update their skill set in the following years in order to accommodate the requirements stemming from the shifting working environment.

These two training objectives directed to law students on the one hand and to lawyers on the other hand are not exclusionary. In fact, educational activities should be planned bearing in mind the needs of both groups. However, the basic training of law students should be a priority in case the differing needs cannot be reconciled. This means that the training of law students should be organized as a part of the law faculty's curriculum, whereas continuous training should be executed primarily through extra-curricular seminars, in which also students can participate. Continuous training should be organized as webinars to allow easy participation.

$\longrightarrow$ seminars and conferences

$\longrightarrow$ providing a channel for keeping informed on advances

\section{For Businesses: Dialogue, Collaboration and Support}

The Lab has the unique possibility of providing a space for mutually beneficial dialogue between different stakeholders. The Lab is also a connection point between businesses and students, which becomes particularly visible in the Lab's match-making service for students looking for thesis themes. In addition to facilitating dialogue, collaboration between the Lab and the private sector could prove out to be fruitful in research projects. Similarly, the Lab's activities such as hackathons and legal tech incubator services contribute to the creation of legal tech scene in Finland. Hackathons could be held either as student-driven or industry-based events, where the Lab would be the organizer and the facilitator of future co-operation. Incubator support would include coaching early stage teams in developing their proof of concept, securing venture and/ or seed funding as well as providing contacts.

$\longrightarrow$ dialogue in seminars and conferences

$\longrightarrow$ The Thesis Bank Initiative

$\longrightarrow$ joint research projects

$\longrightarrow$ legal tech incubator services

\section{For the Public Sector: Dialogue, Recom- mendations and Information for Policy Setting}

The Lab's research activities also hold the goal of creating information to benefit the public sector. In addition to basic research, the Lab's expertise could also be put to use in commissioned and 
practice-based research projects as well as giving recommendations for policy makers. Also the thesis bank could produce useful interaction between public institutions and students. In addition, joint research projects, development projects and hackathons organized by public instances and the Lab could produce beneficial pilot projects and public procurement of software.

The Lab doubles as a forum for dialogue between different stakeholders, which facilitates finding a consensus in the field on what should be Finland's position on a certain matter at international fora.

information through basic research and commissioned studies

$\longrightarrow$ joint research projects

$\longrightarrow$ public procurement by industry-based hackathons

\section{For the Overall Society: Community Relations}

Finland is a small country and a small market, which could also be interpreted as an asset: the context makes it relatively easy to create relevant connections. Active communication stragegy carries more strength in this context. In a small country it is also easier to open the data resources of the public administration for research than it is in a big country. This could create many possibilities of legal tech for Finnish companies.

- study on the perceived justice and the possibilities of facilitating this with technology, what types of issues people face when trying to pursue their rights - creating applications to improve access to justice

\section{Collecting and Disseminating Information on Legal Tech and Digitalization of Legal Services}

One of the project's goals is to establish the Lab as a hub of information, dialogue and collaboration on digitalization of law and legal technology. An important aspect of this is to produce new information on these subjects. However, the Lab should also disseminate already existing information and actively inform its target groups about advances in this field. 


\section{Conclusion}

The objectives described in this report form an ambitious agenda for the Legal Tech Lab. These objectives are the Lab's long-term goals and by aspiring towards these objectives the Lab's work will contribute to improving access to justice with the help of technology. It should be noted that the objectives require continuous and long-lasting effort if they are to be fulfilled. Securing such commitment, in turn, requires co-operation of all stakeholders and sufficient funding for the project.

Hence, the Lab's short-term goals aim at establishing its role as the law faculty's in-house start-up at the University of Helsinki. The activities organized in 2017 and 2018 contribute to this end. In June 2017 the Lab holds an international conference Law and Digitalization - Rethinking Legal Services, which examines the intricate relationship between disruption and regulation, which is the context of legal digitalization. The conference includes a student panel that has the objective of including degree students into the Lab's academic activities, which is necessary for creating the communal aspects for the Lab's future work. Papers presented in the conference will be published as a separate open access compilation later on.

In addition, the Lab intends to produce an empirical research report on the problem areas end users face within the legal system. Such data is crucial for defining the scope and potential of legal digitalization and is also the first step towards establishing a framework for future research. In autumn 2017, the Lab will also launch its thesis bank initiative to encourage co-operation between students and stakeholders from private and public sectors. The Lab's first hackathon aptly named Hack the Law! takes place in October 2017.

Some of these activities are intended to take place annually. The summer conference and the hackathon in the autumn semester will form the Lab's core events each year. In addition to these, meetings of the Lab's advisory board will take place two times a year and will further elaborate the objectives, target groups, themes and activities as the field develops as well as evaluate the Lab's success in meeting these objectives.

\section{Legal Tech Lab in Media:}

Niklas Fagerström, "Robotjurister sänker priset på rättsliga tjänster - i vissa fall behövs ingen mänsklig expert alls", YLE Nyheter 12.3.2017, available at: https://svenska.yle.fi/artikel/2017/03/12/ robotjurister-sanker-priset-pa-rattsliga-tjanster-ivissa-fall-behovs-ingen

Riikka Koulu, "Legal Tech Lab - uusia avauksia oikeusteknologiaan", Oikeus 46:1 (2017), pp. 122129.

"RIGHT NOW: LEGAL TECH LAB - Legal Problems Rethought", in Dittmar \& Indrenius Quarterly Q1, April 2017, available at: http://www.dittmar.fi/ quarterly/2017/q1/legal-problems-rethought_

Fredrik Svärd, "Say Hello to University of Helsinki's Legal Tech Lab", LegalTech.se 10.4.2017, available at: http://www.legaltech.se/blogg/say-hello-to-theuniversity-of-helsinki-legal-tech-lab 
Recommendations and information for policy setting

Students leaming together with professionals

Community relations
Collaboration and support for businesses

Continuous training for lawyers

Research

Collecting and disseminating information on Legal Tech and Digitalization of Legal Services

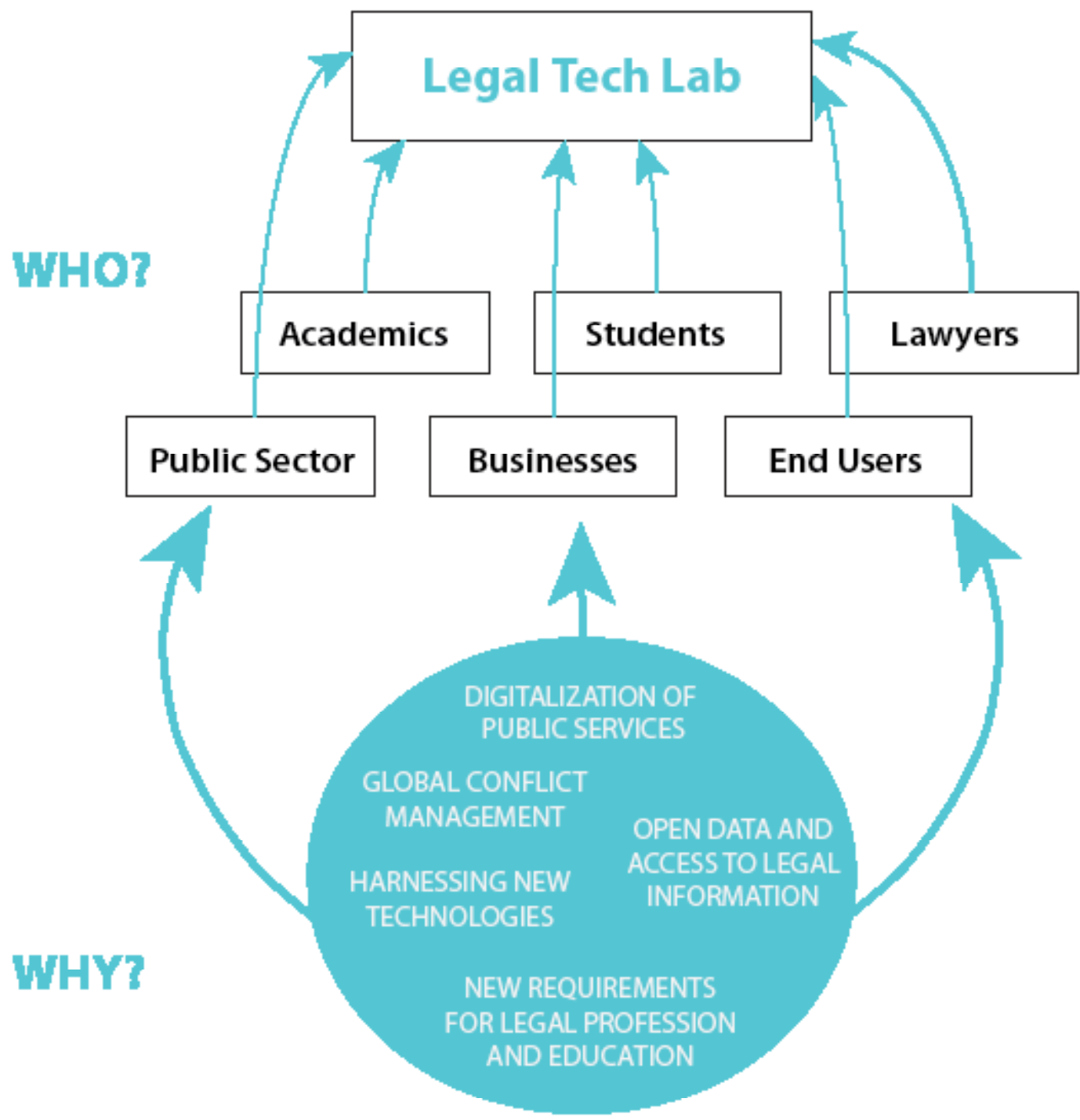

DIGITALIZATION 
Affiliated researchers:

Jenna Påläs

Doctoral candidate, University of Lapland

Jens Kremer

Doctoral candidate, University of Helsinki

Päivi Korpisaari

Professor,

University of Helsinki

Marta Maroni

Doctoral candidate, University of Helsinki

Beata Mäihäniemi Doctoral candidate, University of helsinki,

Marta Cantero Postdoctoral researcher, University of Helsinki

Susanna LindroosHovinheimo

Senior lecturer, University of Helsinki

Jarna Petman

Senior lecturer, University of Helsinki

Juhana Riekkinen Doctoral candidate, University of Lapland

Taina Pihlajarinne Professor, University of Helsinki

Anette Alén-Savikko Postdoctoral researcher, University of Helsinki and University of Lapland
The Advisory Board:

Kimmo Nuotio University of Helsinki

Olli Pitkänen IPR University Center, Hanken

Riku Neuvonen University of Helsinki, University of Tampere

Tuomas Mylly University of Turku

Eero Hyvönen HELDIG

Merja Muilu

The Ministry of Justice

Taru Rastas

The Ministry of

Transport and

Communications

Anniina Dahlström Yle

Anna Ronkainen TrademarkNow

Jaakko Lindgren Dottir

Johanna Rantanen Dottir

Jukka Lång Dittmar \& Indrenius

Johanna Lilja Roschier

Herkko Hietanen Turre Legal

Marko Loisa The Ministry of Justice

Leena Kuusniemi Rovio

Juha Ilola Reaktor

Jakob Storå Superhero Capital

Matti Kari Pieni Piiri

Pilvi Alopaeus Suomen Sopimustieto

Tobias Bräutigam Bird\&Bird

Suvi Uski Someturva

Tom Eklöf Unity Technologies

Matias Markkanen VTT

Markus Oksanen DLA Piper

Taina Kallio
OP 
